\title{
PENGARUH REFRIGERAN CAMPURAN HALOKARBON DAN HIDROKARBON TERHADAP TEMPERATUR EVAPORATOR
}

\author{
Khambali $^{1}$ Listiyono $^{2}$, dan Vinan Viyus ${ }^{3}$ \\ 1,2,3 Jurusan Teknik Mesin, Politeknik Negeri Malang \\ ${ }^{1}$ khambali@polinema.ac.id, ${ }^{2}$ listiyono@polinema.ac.id, ${ }^{1}$ vinanviyus@polinema.ac.id
}

(Artikel diterima: Februari 2020, direvisi: April 2020, diterima untuk terbit: Juli 2020)

\begin{abstract}
Abstrak - Hydrocarbon refrigerant is a type of environmentally friendly refrigerant but it has disadvantages compared to halocarbon refrigerant which is flammable. The purpose of mixing hydrocarbon refrigerants with halocarbons in the study was to determine the effect of the percentage of the refrigerant mixture on the temperature of the evaporator and reduce its flameability. The percentage of the mass of the mixed refrigerant mixture that is loaded and time is used as the independent variable, the evaporator temperature as the dependent variable. So the relationship between time and evaporator temperature will be known for each percentage of the mass of the refrigerant mixture. Hasil penelitian menunjukkan bahwa komposisi campuran massa refrigeran hidrokarbon dengan halocarbon berpengaruh terhadap laju perubahan temperatur evaporator. Persentase hidrokarbon dalam campuaran refrigeran HC-HCFC semakin besar dapat meningkatkan laju penurunan temperatur pada evaporator. Semakin besar persentase hidrokarbon dapat menghasilkan pencapaian temperatur semakin rendah pada evaporator.
\end{abstract}

Kata kunci: refrigerant, hydrocarbon, evaporator.

\section{Pendahuluan}

Semua sistem refrigerasi bekerja dengan menggunakan refrigeran sebagai fluida kerjanya. Refrigeran yang dimasukkan ke dalam refrigerator berfungsi untuk menyerap panas dan membuang panas. Penyerapan panas terjadi pada evaporator, sedang pembuangan panas terjadi pada kondensor. Kinerja mesin refrigerasi dipengaruhi oleh kemampuan komponen-komponen utamanya untuk berfungsi sesuai dengan fungsi masing-masing, jenis refrigeran, dan kuantitas refrigeran yang diisikan ke dalam mesin refrigerasi. Selain itu jumlah refrigeran yang dimasukkan ke dalam refrigerator ikut berpengaruh pada kemampuan dan kecepatan evaporator menyerap panas di lingkungan sekitarnya.

Jumlah refrigeran yang diisikan ke dalam refrigerator dapat divariasikan begitu pula dengan jenis refrigerannya. Jenis refrigeran yang banyak dipakai pada saat ini HCFC (hidrochlorofluorocarbon) dan HFC (hydrofluorocarbon) yang memiliki sifat-sifat baik ditinjau dari segi teknik seperti: kestabilan yang tinggi, tidak mudah terbakar, tidak beracun dan relatif mudah didapat. Namun refrigeran yang mengandung unsur fluor dan chlor terdapat banyak kekurangan yang berpengaruh terhadap lingkungan. Refrigeran yang mengandung unsur chlor dapat merusak lapisan ozon (Ozone Depleting Potential / ODP) dan yang mengandung unsur flour dapat menimbulkan pemanasan global (Global Warming Potential / GWP) apabila refrigeran tersebut terlepas ke atmospher. Pemakaian hidrokarbon sebagai refrigeran pengganti merupakan salah satu alternatif solusi untuk mengatasi masalah ini, karena refrigeran hidrokarbon tidak mempunyai efek negatif terhadap lingkungan. Dimana refrigeran ini tidak memiliki unsur chlour yang dapat merusak lapisan ozon atau nilai ODP-nya sama dengan nol, juga tidak mengandung unsur flour yang dapat menimbulkan pemanasan global. Tetapi refrigerant hidrokarbon memiliki kelehahan yaitu mudah terbakar. Salah satu upaya untuk mengurangi sifat mudah terbakar refrigerant hidrokarbon adalah dengan cara mencampur dengan refrigerant halocarbon.

\section{Tinjauan Pustaka}

Beberapa riset mengenai sifat-sifat dan kinerja berbagai campuran jenis refrigeran halokarbon dan hidrokarbon dan kondisi temperatur pada evaporator refrigerator telah dilakukan oleh beberapa peneliti terdahulu, dengan variasi yang beragam antara lain:

Purnomo (2017) telah melakuan penelitian tentang pencampuran refrigeran hidrokarbon Musicool R134 dengan $\mathrm{CO} 2$ yang dalam kesimpulannya mengatakan bahwa ketercapaian tekanan discharge dipengaruhi oleh karakteristik masing-masing refrigeran. Hasil penelitiannya memberikan ilustrasi bahwa setiap kenaikan konsentrasi CO2 akan meningkatkan tekanan di sisi keluar kompresor.

Jabaraj (2016) meneliti tentang beberapa refrigeran hidrokarbon R290 dan campuran antara refrigerant R404a dan R410a menyimpulkan "Nilai kinerja refrigerator dipengaruhi oleh beberapa hal di antarannya adalah kuantitas massa isian refrigeran. Temperatur kondensor juga berpengaruh pada nilai kinerja refrigerator. Kinerja R290 sama dengan R410a, sedangkan kinerja R404a 6,5\% lebih tinggi dari R290 pada temperatur kondensor 46 oC s.d. 47.6 oC"

Domanski (2014) telah meneliti karakteristik perpindahan panas pada condensor dan evaporator menggunakan refrigeran Hidrokarbon menyatakan bahwa Refrigeran alami, HC diharapkan menjadi refrigeran alternatif yang populer seperti pada umumnya R-22 (HCFC) sebab bentuk refrigeran ini lebih baik dari R-22 dan lebih ramah lingkungan. Diantara $\mathrm{HC}$, koefisien perpindahan panas pada kondensor R-1270 adalah lebih tinggi di dalam fluk massa antara 50 sampai 200 $\mathrm{kg} / \mathrm{m} 2, \mathrm{R}-1270$ juga menunjukkan koefisien perpindahan panas kondensasi rata-rata yang lebih tinggi, R-290 dan R600a membentuk koefisien perpindahan panas kondensasi rata-rata yang sedikit kecil dari R-1270 tetapi menunjukkan kecenderungan yang sama. Korelasi Cavallini-zecchins's berada di sekitar hasil-hasil koefisien perpindahan panas kondensasi. Koefisien-koefisien perpindahan panas lokal meningkat dengan peningkatan kualitas refrigeran di dalam evaporator. Sementara itu koefisien-koefisien perpindahan panas local HC lebih dari R-22 diantara semua refrigeran- 
refrigeran $\mathrm{HC}, \mathrm{R}-1270$ menunjukkan koefisien

perpindahan panas evaporasi rata-rata tertinggi. Korelasi terbaik Kandlikar sesuai dengan hasil-hasil eksperimen untuk perpindahan panas evaporasi.

Ichsan (2013) meneliti tentang variasi pendinginan pada evaporator pada low Stage sistem refrigerasi cascade R22404A yang dalam penetiannya menggunakan sistem refrigerasi cascade yang disusun atas dua stage yaitu high stage dan low stage dimana low stage yang dihubungkan dengan heat exchanger tipe konsentrik untuk memindahkan panas dari kondensor low stage menuju evaporator high stage. Pada pengujiannya diberikan beban pendinginan sebesar sepuluh variasi heater, yang variasi bebannya mulai dari tanpa pemberian beban sampai beban heater sebesar 203,72 Watt. Hasil penelitiannya menunjukkan bahwa hasil yang optimum pada pembebanan 203,72watt berupa COP cascade 1,06213, e effectiveness 0,78313 , temperatur evaporator minimum $-26,9$ ${ }^{\circ} \mathrm{C}$. Hasil tersebut menunjukkan desain heat exchanger tipe konsentrik sangat menentukan dalam perpindahan panas, sehingga performa dari sistem refrigerasi cascade sangat ditentukan oleh tingkat perpindahan panas pada heat exchanger yang diketahui melalui nilai e effectiveness dan NTU.

Safitra (2013) meneliti tentang variasi beban pendinginan di evaporator low stage sistem refrigerasi cascade menggunakan heat exchanger tipe concentric tube dengan fluida kerja refrigeran musicool-22 di high stage dan R-404a di low stage. Penelitiannya dilakukan dengan memvariasikan beban pendinginan di evaporator low stage menggunakan electric heater. Variasi daya mulai dari 0 (tanpa beban), 11, 35, 70, 95, 140, 210, dan 300 Watt. Hasil penelitiannya menunjukkan bahwa nilai-nilai optimum untuk proses pembekuan daging yaitu pada pembebanan 35 Watt dengan Qevap $=0,327 \mathrm{~kW}$, COPcas $=0,935$ dan temperatur di dalam cooling box sebesar $-26,2{ }^{\circ} \mathrm{C}$. Pada beban 300 Wat diperoleh kapasitas pendinginan maksimum pada sistem Low Stage sebesar 0,622 kW. Kerja maksimum kompresor pada sistem High Stage 0,148 kW dan Low Stage 0,461 kW, nilai COP cascade maksimum 1,020, efek refrigerasi maksimum pada Low Stage 135,865 kJ/kg, HRR maksimum pada Low Stage 1,742 Kemudian diperoleh nilai effectiveness cascade heat exchanger tertinggi 0,93 dan terendah 0,89 serta nilai NTU tertinggi 7,06 dan terendah 4,76 pada saat beban 300Watt.

Sukamto (2014) dalam penelitiannya tentang kinerja mesin pendingin menggunakan liquid suction subcooler dengan variasi temperature lingkungan dalam analisisnya mununjukkan bahwa terjadi menunjukkan bahwa terjadi peningkatan kapasitas pendinginan sebesar $0.91 \%$ hingga $10.27 \%$ pada temperatur lingkungan 30,35 dan 40 oC. Selain peningkatan kapasitas pendinginan, juga dihasilkan peningkatan kerja kompresor, yaitu sebesar $0.52 \%$ hingga $5.07 \%$ untuk temperatur lingkungan 30,35 dan $40 \mathrm{oC}$. 0leh karena persentase peningkatan kapasitas pendinginan lebih tinggi dari peningkatan konsumsi daya, maka penggunaan liquid-suction subcooler juga meningkatkan COP (coefficient of performance), yaitu sebesar $0.39 \%$ hingga $4.95 \%$ untuk temperatur lingkungan 30, 35 dan 40oC. Pada kajian ini juga ditemukan bahwa untuk derajad subcooling yang sama, semakin tinggi temperatur lingkungan semakin besar pula peningkatan COP pada mesin pendingin.

\section{Metode Penelitian}

Pada pengujian ini dilakukan dengan mengamati perubahan temperatur refrigerator terhadap waktu pada refrigerator. Presentase campuran massa refrigeran hidrokarbon dan halokarbon digunakan sebagai variabel bebas sedangkan temperatur evaporator digunakan sebagai variabel terikat. Pengujian dilakukan terhadap refrigerator dengan mengisi dengan refrigeran campuran hidrokarbon MC-22 dengan halokarbon R22. Dimulai dengan menguji refrigerator yang diisi dengan $100 \%$ refrigeran hidorokarbon MC-22, kedua diisi denga 100\% refrigeran halokarbon R22. Ketiga dan seterusnya disi dengan campuran refrigeran hidrokarbon dan halokarbon dengan persentase campuran bervariasi.

\section{Hasil Penelitian dan Pembahasan}

Dari data hasil pengamatan yang telah diperoleh untuk beberapa isi refrigeran yang dimulai dari pengisian 100\% hidrokarbon MC-22, 100\% refrigeran halokarbon R22, dan refrigeran campuran hidrokarbon dengan halokarbon dengan komposisi 75\% HC - 25\% HCFC, 80\% HC - 20\% HCFC, dan $90 \%$ HC - 10\% HCFC yang diolah menjadi sebuah grafik yang menunjukkan hubungan antara campuran refrigeran hidrokarbon MC-22 dengan halokarbon R22 terhadap perubahan temperatur seperti yang terlihat pada Gambar 1 sampai dengan Gambar 8 berikut.

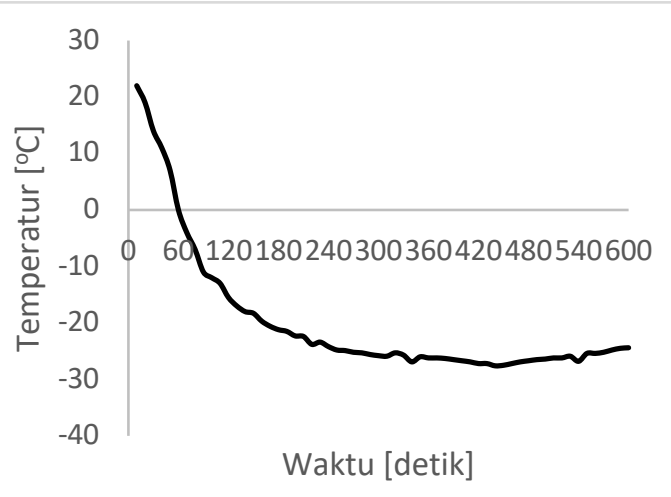

Gambar 1. Pengaruh isi $100 \%$ refrigeran hidrokarbon terhadap terhadap perubahan temperatur evaporator

Pada Gambar 1 adalah kondisi temperatur evaporator yang menggunakan $100 \%$ refrigeran hidrokarbon yaitu sebesar $175 \mathrm{~g}$. Massa yang diisikan terbut adalah isian optimal untuk mesin refrigerator yang digunalkan dalam penelitian ini. Pada Ganbar 4.1 terlihat adanya penurunan temperatur secara cepat untuk rentang waktu 0 sampai dengan 90 detik. Dalam waktu satu setengah menit temperatur evaporator sudah bisa mencapai -11 oC. Setelah 90 detik laju penurunan temperatur evaporator terlihat sedikit mengalami penurunan. Kondisi tersebut berlangsung sampai waktu 440 detik. Setelah 440 detik kondisi temperatur evaporator mengalami kenaikan secara perlahan. 


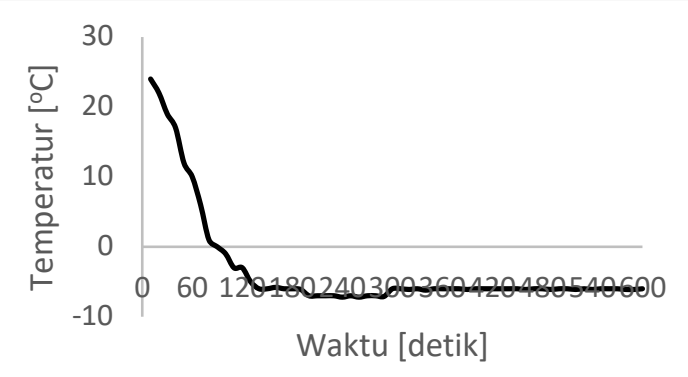

Gambar 2. Pengaruh isi $100 \%$ refrigeran halokarbon terhadap terhadap perubahan temperatur evaporator

Gambar 2 adalah grafik yang menunjukkan laju perubahan temperatur evaporator jika refrigerator diisi dengan $100 \%$ refrigeran halokarbon R22. Berdasarkan penelitian yang kami lakukan sebelumnya jumlah massa isian optimalnya adalah $425 \mathrm{~g}$. Pada gambar tersebut terlihat bahwa laju perubahan temperatur secara signifikan terjadi sejak mesin refrigerator dihidupkan hingga 80 detik pertama. Kemudian laju perubahan temperatur mengalami perubahan atau mengalami perlambatan untuk rentang waktu 80 sampai 140 detik. Temperatur evaporator mengalami sedikit fluktuatif untuk rentang waktu 140 hingga 300 detik. Setelah 300 detik kondisi temperatur pada evaporator stabil pada -6 ${ }^{\circ} \mathrm{C}$

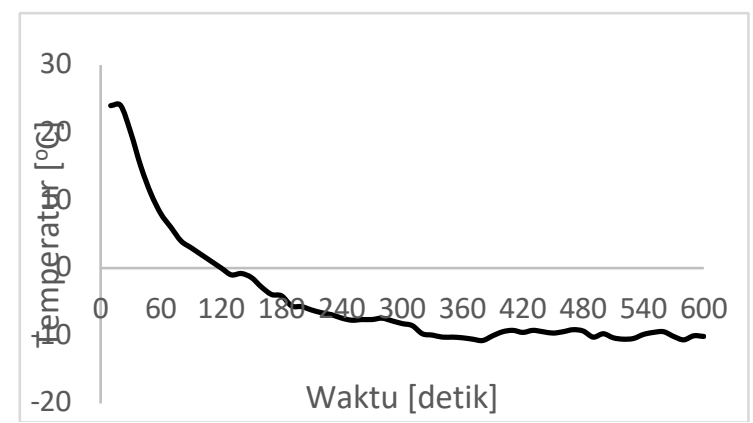

Gambar 3 Pengaruh jumlah massa refrigeran campuran hidrokarbon halokarbon terhadap terhadap perubahan temperatur evaporator untuk komposisi massa $75 \% \mathrm{HC}-25 \% \mathrm{R} 22$

Gambar 3 adalah grafik yang menunjukkan perubahan temperatur evaporator jika refrigerator diisi dengan $75 \% \mathrm{HC}$ - 25\% R22. Pada gambar tersebut terlihat bahwa grafik perubahan temperatur evaporator mirip dengan grafik yang dihasilkan jika refrigerator diisi dengan 100\% refrigeran hidrokarbon. Yang membedakan keduanya adalah pencapaian temperatur untuk isian campuran $75 \% \mathrm{HC}-25 \%$ R22 tidak serendah yang isian $100 \%$ hidrokarbon. Komposisi campuran ini hanya bisa mencapai temperatur terendah -11 ${ }^{\circ} \mathrm{C}$ sedangan untuk yang $100 \%$ hidrokarbon bisa mencapai temperatur sangat rendah yaitu $-25^{\circ} \mathrm{C}$. Penurunan temperatur evaporator terjadi sangat signifikan setelah refrigerator dihidupkan hingga 125 detik. Untuk rentang waktu 125 hinnga 380 detik laju penurununan temperatur evaporator mengalami perlambatan. Setelah 380 detik kondisi temperatur evaporator relatif konstan, hanya mengalami flutuasi kecil.

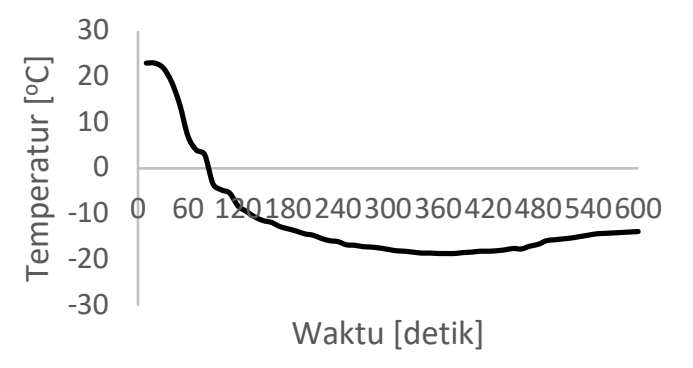

Gambar 4. Pengaruh jumlah massa refrigeran campuran hidrokarbon halokarbon terhadap terhadap perubahan temperatur evaporator untuk komposisi massa $80 \% \mathrm{HC}-20 \% \mathrm{R} 22$

Gambar 4.5 adalah kondisi temperatur evaporator untuk refrigeran campuran $80 \% \mathrm{HC}-20 \%$ R22. Pada gambar tersebut terlihat mirip dengan gambar yang dihasilkan campuran refrigeran $75 \% \mathrm{HC}-25 \% \mathrm{R} 22$. Perbedaan kedua grafik adalah untuk campuran $80 \%$ HC - 20\% R22 pencapaian temperaturnya lebih rendah daripada yang menggunakan refrigeran campuran $75 \% \mathrm{HC}-25 \% \mathrm{R} 22$. Temperatur evaporator mengalami sedikit kenaikan setelah 350 detik, sedangkan yang campuran $75 \% \mathrm{HC}-25 \% \mathrm{R} 22$ relatif stabil.

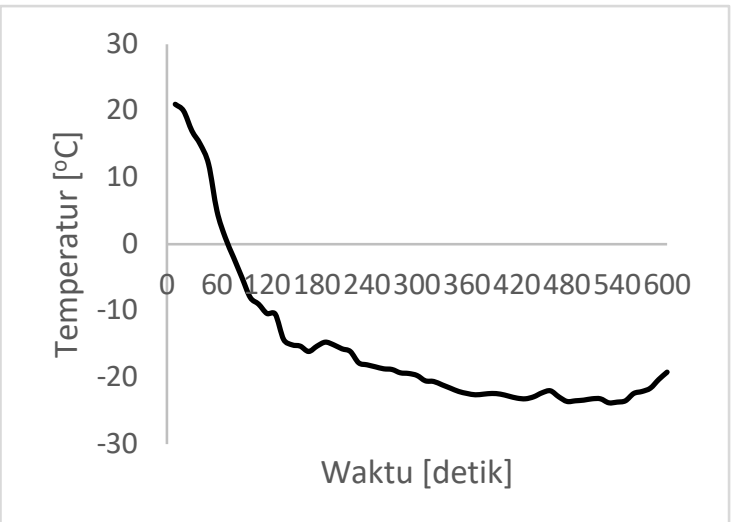

Gambar 5. Pengaruh jumlah massa refrigeran campuran hidrokarbon halokarbon terhadap terhadap perubahan temperatur evaporator untuk komposisi massa $90 \% \mathrm{HC}-10 \% \mathrm{R} 22$

Gambar 5 adalah kondisi temperatur evaporator untuk komposisi massa 90\% HC - 10\% R22. Pada gambar tesebut terlihat bahwa setelah refrigerator dihidupkan telah terjadi penurunan temperatur yang cepat pada rentang waktu antara 0 sampai dengan 80 detik yaitu dari $25{ }^{\circ} \mathrm{C}$ sampai $-15{ }^{\circ} \mathrm{C}$. Setelah 80 detik temperatur evaporator terus mengalami penurunan secara perlahan hingga pada detik ke 300 . Temperatur evaporator terlihat mengalami kestabilan pada rentang waktu 300 sampai dengan 450 detik. Setelah dicapai waktu 450 detik dan seterusnya temperatur evaporator menunjukkan adanya kenaikan kecil.

Dari grafik hubungan antara jumlah massa refrigeran hidrokarbon terhadap perubahan temperatur evaporator yaitu Gambar 4.2 sampai dengan Gambar 4.6 jika digabungkan akan mengasilkan grafik seperti yang ditunjukkan pada Gambar 4.7. Gambar 4.7 memperlihatkan bahwa pencapaian temperatur evaporator paling rendah dihasilkan jika refrigeroator diisi dengan 100\% refrigeran hidrokarbon. Pada gambar di atas juga terlihat bahwa semakin kecil komposisi refrigeran R22 dalam campuran $\mathrm{HC}$ - R22 maka pencapaian temperatur evaporator akan semakin rendah pula. 


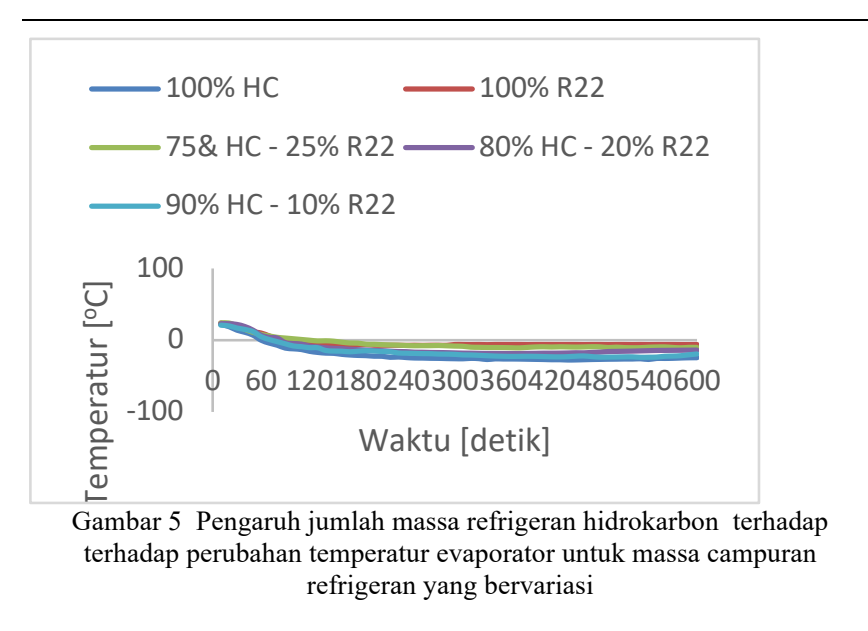

\section{KESIMPULAN DAN SARAN}

\section{A. Kesimpulan}

Dari pembahasan yang telah dilakukan terhadap hasil penelitian maka dapat ditarik kesimpulan untuk penelian ini adalah sebagai berikut:

1. Komposisi campuran massa refrigeran hidrokarbon dengan halocarbon berpengaruh terhadap laju perubahan temperatur evaporator.

2. Persentase hidrokarbon dalam campuaran refrigeran HCHCFC semakin besar dapat meningkatkan laju penurunan temperatur pada evaporator.

3. Semakin besar persentase hidrokarbon dapat menghasilkan pencapaian temperatur semakin rendah pada evaporator.

\section{B. Saran}

Berdasarkan hasil penelitian yang telah kami lakukan, maka saran-saran yang kami berikan untuk penelitian selanjutnya adalah:

1. Perlu dilakukan penelitian untuk campuran jenis

refrigerant hidrokarbon dan halocarbon yang lain

\section{DAfTar Pustaka}

[1] Domanski, Piotr A., Yasar David, Kim Minsung, 2005. Performance of a finned-tube evaporator optimized for different refrigerants and its effect on system efficiency, National Institute Standart Technology, International Journal of Refrigeration 28 (2005) 820-827

[2] Domanski, Piotr A. 2014. Properties and Cycle Performance of refrigeran Blends Operating Near and Above the Refr, Performance of HC and HFC Refrigeran in a Finned-Tube Evaporator and its Effect on System Efficiency, National Institute Standart Technology

[3] Ichsan, Moch. Munirul, Khrisna Putra, Ary Bachtiar, 2013, Studi Variasi Beab Pendinginan pada Evaporator pada Low Stage Sistem Refrigerasi Cascade R22-404a, Jurnal Teknik POM ITS, Vol.2 no. 1.

[4] Nigusse, Haile Araya, Ndiritu, Hiram M. Kiplimo, Robert. 2014. Performance Assessment of a Shell Tube Evaporator for a Model Organic Rankine Cycle for Use in Geothermal Power Plant, Journal of Power and Energy Engineering, 2014, 2, 9-18

[5] Safitra, Arrad Ghani, Khrisna Putra, Ary Bachtiar, 2013, Studi Variasi Beban Pendinginan Di Evaporator Low Stage Sistem Refrigerasi Cascade Menggunakan Heat Exchanger Tipe Concentric Tube Dengan Fluida Kerja Refrigeran Musicool-22 Di High Stage Dan R-404a Di Low Stage, JURNAL TEKNIK POMITS Vol. 2, No. 1.

[6] Sukamto, A.P. Edi, Pangripto, Triaji, Sumeru, Henry Nasution, 2014, Analisis Energi Peningkatan Kinerja Mesin Pendingin
Menggunakan Liquid-suction Subcooler dengan Variasi Temperatur Lingkungan, Proceedings Seminar Nasional Teknik Mesin Universitas Trisakti, SNTMU [ [6] Harianto and E. Yawara, "Efektifitas Penggunaan Thermostatic Expansion Vave pada Refrigerasi AC Split," Sekol. TINGGI Teknol. Nas., vol. 8, pp. 189-192, 2013. 